\title{
Correspondence
}

\section{Punctate keratopathy}

\section{To the Editorial Committee of the British Journal of Ophthalmology}

SIRs,-I was interested to read the paper by Rice, Jones, and Ashton ( I968) entitled "Punctate Keratopathy of West Indians". This punctate keratopathy can be seen in: many Negro eyes inside and outside onchocerciasis areas and should further warn tropical $\vec{\omega}$ ophthalmologists to be careful before diagnosing ocular onchocerciasis on the strength of a punctate keratopathy (Rodger, 1957).

PRINCESS MARGARET HOSPITAL, Yours faithfully, F. C. Rodger

OKUS ROAD, SWINDON, WILTS.

March 4, I969

\section{References}

RiCE, N. s. C., JONES, B. R., and AShton, N. (1968) Brit. J. Ophthal., 52, 865

RODGER, F. C. (I957) Ibid., 4r, 599

\section{Book reviews}

Ocular Mycoses (Les mycoses oculaires). By J. François, M. Elewaut-R ysselaere, and E. DE Vos. 1968. Pp. 371, 190 figs, bibl. Masson, Paris. (NF.120)

This is a precise and detailed account of immense value. The aim of the study is to remind ophthalmologists of the importance of ocular mycotic infections and to urge them to think more often of mycosis when faced with an atypical infection of the cornea or eye. The conditions most frequently seen are actinomycosis of the lacrimal canaliculi, aspergillosis of the cornea, mucormycosis of the orbit, and post-operative mycotic endophthalmitis.

The first part deals with concepts of general and ocular pathology-diagnosis and a study of the. factors which influence mycotic infection. The mycotic flora of the conjunctival sac are enumerated. N Many figures, tables, and references add to the interest of this section, which ends with a general discussion on the therapy of ocular mycosis. There is as yet no specific treatment.

In the second part the authors present a systematic study of ocular mycosis and pseudo-mycosis, listing actinomycosis, aspergillosis, blastomycosis, cephalosporosis, chromoblastomycosis, cladosporiosis, coccodioidomycosis, dermatophytes, geotrichosis, histoplasmosis, levurosis, candidiasis, cryptococcosis, pityrosporosis, maduramycosis (mycetoma), and mucormycosis (phylomatosis). The work reported is that undertaken by international investigators specializing in this field and is concise and very comprehensive. Finally, penicilliosis, rhinosporidiosis, and sporotrichosis are reviewed.

An extensive bibliography is given with each chapter. 